\title{
Occupational Stress as a Predictor of Mental Health Status of Universities Lecturers in South-East Nigeria
}

\author{
Lilian Ifeoma Akunne* Vera Nwadinobi $(\mathrm{PhD}) \quad$ Anulika Valantina Etele $(\mathrm{PhD})$ \\ Juliana Akuezilo (PhD) \\ Department of Guidance and Counselling, Nnamdi Azikiwe University, \\ PO box 5025, Awka Anambra State, Nigeria
}

\begin{abstract}
The focus of this study was to determine occupational stress as a predictor of mental health status of universities lecturers in south-east Nigeria. three research questions and three hypotheses guided the study. The study adopted the correlation survey research design. A sample of 940 lecturers were selected using the multistage sampling procedure. The instrument adopted for data collection is the Occupational Stress Inventory Revised Edition (OSIR) which was developed by Samuel H. Osipow in 1998 and The Depression Anxiety Stress Scale (DASS-21) developed by Lovibond and Lovibond in 1983. The administration of the instrument was done through direct delivery approach to the Lectures, in administering the instrument, A total of $920(100 \%)$ questionnaires were administered with a retrieval rate of 902 (98\%). Data collected were analyzed using multiple regression analysis. The study revealed that occupational stress of lecturers between 20-40 years of age had contributed to 51.0 percent and is a significant predictor of their mental health, occupational stress of lecturers within 40 years and above had contributed to 72.0 percent of their mental health and occupational stress of lecturers within 40 years of age is a significant predictor of their mental health. the findings further revealed that that occupational stress of lecturers jointly with age had contributed to 72.0 percent and 6.2 percent respectively of their mental health and occupational stress and age of lecturers is a significant joint predictor of their mental health. Based on the strength of this findings, conclusions were drawn and recommendations made among others that Routine medical check on the mental health status of lecturers should be sponsored by federal and state governments for lecturers in federal and state institutions respectively.
\end{abstract}

Keywords: Occupation, Stress, Occupational Stress, Mental Health, Lecturers, Universities

DOI: $10.7176 / \mathrm{JEP} / 12-34-04$

Publication date: December $31^{\text {st }} 2021$

\section{Introduction}

The World Health Organisation along with the International Labour Organisation recently reported that long working hours led to 754,000 deaths from stroke and ischemic heart disease in 2016 and beyond, showing a $29 \%$ increase since 2000. According to the report, substantial number of strokes and heart diseases resulted from working at least 55 hours a week compare to working 35 to 40 hours a week. A study by Akinade in Adebiyi (2013), stated that Nigerians are working harder and longer hours (especially those in some demanding professions) which include lecturing. Stress forms part of the day-to-day activity of an individual. For instance, students may experience stress in a course of studying, similarly housewives may experience stress in managing the home affairs, as well as businessmen and employee on their jobs. Reasons recorded for stress experienced differs from person to person due to variations in people's mental health.

According to Adenuga (2015), stress is one of the leading causes of employees' discontentment with their jobs. Furthermore, Branham in Adenuga, (2015) asserted that, it seems clear that one quarter to one half of all workers feel some level of dysfunction due to stress, which undoubtedly impacts negatively on their work productivity and can lead to their work turnover. This goes to mean that stress can have many causes, including when organization cannot or will not supply the tools necessary to produce or work efficiently while on the job. Stress in general can be propelled intrinsically or extrinsic among employees in the workplace. People react to stress in different ways, some coping much better than others and suffering fewer of the harmful effects in their behaviour and wellbeing. Just as stress differ based on individual, it also differs as a function of an individuals' occupation. Some occupations are, inherently more stressful than others. All of the stress-strain-health relationships have an obvious impact on the organization and industry. Occupational stress is becoming increasingly globalized and affects all countries, all professions and all categories of workers, as well as families and society in general (Olanrewaju, 2015).

Intrinsic stress related to organization is referred to as occupational stress. Occupational stress is a condition in which job related factors interact with the workers to change his or her physiological condition such that he or she deviate from normal functioning (Felicia \& Ofoegbu in Adebiyi, 2013). Occupational stress has been observed as a variable that adversely affects the individual health as well as its productivity in the workplace and often times lead to death. In the same vein, major change initiatives, excessive work hours, heavy workloads, poor management, diminishing resources, unfavourable student to staff ratios, pressure to attract external funds, 
insecurity, lack of recognition and reward, and role ambiguity, have frequently been reported by Lecturers in the universities as correlates of occupational stress.

However, according to Nwimo and Onwunaka (2015) a bit of stress is necessary to gain outstanding success. Because of this, successful people are those who convert their stress to creative energy and creative power. Some experts argue that those who work in a moderate level of stress work with a higher performance (Steers in Nwimo \& Onwunaka, 2015). Besides, a moderate level of stress may have a motivating effect if the individual's comprehension of roles is positive (Hargrove, Quick, Nelson, \& Quick, 2011). Each profession causes a specific level of stress. However, teaching is one of such profession that causes more stress compared to other professions.

Stress in the learning environment affects both the teacher and the learners in the teaching process. Kyriacou in Nwimo and Onwunaka (2015) who has conducted varied studies on teacher stress, defined teacher stress as the experiencing of unpleasant feelings such as depression, anger, worry, irritableness and tension which are formed as a result of working as a teacher/lecturer. This situation is not peculiar to secondary education level but to tertiary institutions in developed nations as well as developing country, Nigeria. Stress among lecturers has prevailed despite the nation's declaration of the importance of university education in national development and the role it plays in satisfying human needs. However, there are growing evidence that no Nigerian university either private or government owned can genuinely claim to be immune from stress (Adebiyi, 2011). This is a scenario where by, university lecturers in Nigeria grapple daily with overcrowded classrooms, outdated laboratory facilities for research activities and teaching, poor working condition among others.

Similarly, the striving slogan in Nigerian universities 'publish or perish syndrome' is a major stressor. This is a scenario where intense pressure is piled on lecturers (especially the younger ones) to publish as many papers as possible in the shortest possible time for promotion. Other commonly cited sources of stress in Nigerian public universities include strenuous promotion criteria/guidelines, heavy academic workload and frustration in the efforts taken for articles to be published in local journals among others. These sources of stress as Akinmayowa and Kadiri (2014) pointed out, were not only influencing negatively how academic staff functions in public universities in Nigeria but also their overall well being of which mental health is inclusive.

The concept of mental health has been described as is a psychological state of wellbeing, growth, a sense of purpose in life, self acceptance and positive relations with others (Adenuga, 2015). He further defines mental health as the adjustment of the individual to himself and to the society so that he can face the realities of life and function most effectively with the greatest satisfaction, cheerfulness and acceptable behaviour. Thus individuals with mental illness are unable to believe in themselves, distrust people, are unable to cope with daily problems of life and have problems relating to others. Moronkola in Adenuga (2015) identifies the following as the characteristics of good mental health, an individual having ability to forgive self and others; considering other people's interest as well as self interest; respect other people's opinions and rights and dealing with problems as they come. Also, believing in self and to pursue ideals that are worthwhile, setting realistic goals, thinking and making rational decisions and be part of a worthwhile group as well as relaxing and sleeping well.

Studies have revealed evidence to prove that tertiary institutions in Nigeria (whether private or government) is stress resistant (Adebiyi, 2011). The official aim of the annual NUC accreditation assessment is to ensure that universities comply with the commission's standard as contained in its 1995-99 report, which recommended a student-to-lecturer ratio of 9:1 for agriculture and engineering-technology faculties, 6:1 in human and veterinary medicine faculties and 10:1 in science and pharmacy faculties, while law, social sciences and arts should be 20:1 (Alex, 2019). Some of the challenges faced by lecturers in Nigeria education system include among others are lack of technology which impedes their ease of assignment and delivery, demand and supply of the university education, large number of students in lecture halls especially in the Federal and State Universities and increase in school fees versus the quality of education dished out due to lack of motivation or incentives to encourage lecturers in their delivery of knowledge (Ukpai, 2016).

Demographic variables/factors related that are proven to relate to someone's job stressor/health relationships include gender, age, marital status, job tenure, job title, and hierarchical level. Among these variables, gender, age and hierarchical level were found to be the most significant. However, rapid aging has had an enormous influence on the labour environment, organizations, and society. As population aging becomes a global trend, exhaustion and prolonged working age have been issues for older workers (Walker, 2015). Active aging is expected not only to prolong working years but also to increase age integration and reduce intergenerational conflicts (Dykstra \& Fleischmann, 2018). The willingness to work and the effects of working ability on health and well-being could be the core issues for an aging society. However, whether the negative impacts of exhaustion on well-being can be reduced or avoided via individuals' working methods or attitudes, or by systemic and policy changes for both younger and older workers has been little explored. A complex relationship appears to exist between occupational stress and age. According to a study conducted by Mahmood, Saira Nudrat and Zahoor (2013), a significant difference between stress among age groups, but these differed according to the stressors. In the same study the oldest group of teachers/Lectures (aged over 40 years) reported higher levels of stress from curriculum demands than their younger colleagues. It is documented that younger people present higher levels of emotional exhaustion 
as compared to their older colleagues. This propels the present study which investigated occupational stress as predictor of mental health status of University lecturers in South-east Nigeria. Age of lecturers is introduced in the present study as moderator variable, hence the study specifically determined:

- Occupational stress as predictor of mental health status of University Lectures in South-east, Nigeria within 20 - 40 years.

- Occupational stress as predictor of mental health status of University Lecturers in South-east, Nigeria within 40 years and above.

- Occupational stress and age as joint predictor of mental health of University Lecturers in South-east, Nigeria.

\subsection{Research Questions}

- Does occupational stress predict mental health of university Lecturers in South-east, Nigeria between 20 -40 years of age?

- Does occupational stress predict mental health of university Lecturers in South-east, Nigeria between 40 years and above?

- How does occupational stress and age jointly predict mental health of university Lecturers in South-east, Nigeria?

\subsection{Hypotheses}

- There is no significant relationship between occupational stress and mental health of University Lecturers in South-east, Nigeria within 40 years below.

- There is no significant relationship between occupational stress and mental health of University Lecturers in South-east, Nigeria within 40 year above.

- There is no significant relationship among occupational stress, Age and mental health of University Lecturers in South-east, Nigeria.

\section{Review of Related Literature}

Adenuga (2015) carried out a study on the impact of occupational stress on job satisfaction and mental health of First Bank employees, Lagos-East, Lagos, Nigeria. The study used ex-post facto research design; simple random sampling techniques were used to select 100 samples (bank employees) from Lagos-East Senatorial District of Lagos State, Nigeria. The age ranges of samples were between 21 and 52 years. The mean range and standard deviation of the samples were 30.6 and 3.28. Three validated instruments were used in collecting data and Simple Regression Analysis was used to analyze data. The results indicated that there is no significant relationship in the occupational stress and mental health of bank employees; also, it was found that there is significant relationship in the occupational stress and job satisfaction of bank employees. The results further revealed that occupational stress predicted job satisfaction and mental health. Based on the findings, it was suggested that mental health and job satisfaction of the bank employees be given greater attention. This study relates with the present study as both have occupational stress as their independent variable but differ in terms of subject of the study, design designs and location of the study.

Agbor, Ebeh and Onyeanu (2018) carried out a study on Predictors of students' mental wellbeing among 348 undergraduates selected through random cluster sampling from the Faculties of Social Sciences of three higher institutions in Eastern Nigeria. Participants' ages ranged from 16 to 33 years, with a mean age of 23.15 and a standard deviation of 3.46. Variables considered include academic stress, substance abuse, age and institution type. Descriptive Cross-Sectional Design was employed while Standard Multiple Regression was adopted for data collection and analyses respectively. Results revealed that academic stress, substance abuse and age had significant negative relationship with mental wellbeing whereas mental wellbeing did not differ across gender $(\mathrm{P}<.01)$. Recommendation was made on the awareness of the implications of drug use and the re-structuring of academic programmes that can minimize stress. Also, the need for a free functional counselling unit to enable students obtain professional advice that will help promote mental well-being was advocated. Both studies relate on the variable under study which is mental health but they differ on research design, subject of study and area of the study.

Kabito, Wami, Chercos and Mekonnen (2020), conducted a study on Work-related Stress and Associated Factors among Academic Staffs at the University of Gondar, Northwest Ethiopia: An Institution-based Crosssectional Study. The design was a cross-sectional study conducted from March to April 2018. Stratified sampling technique was used to select 535 study participants. To measure work-related stress, pre-tested and structured selfadministered University and College Union stress questionnaire. Finally, a significant association was established at $\mathrm{p}<0.05$ and adjusted odds ratio (AOR) with $95 \%$ confidence intervals (CI) in the multivariable model. From the findings, the overall prevalence of work-related stress in 12 months was $60.4 \%$ [95\% CI (57.4, 63.5\%)].The multivariable logistic regression analysis showed that smoking cigarette (AOR: $2.84,95 \%$ CI $(1.25,6.50)$, high 
job demand (AOR: 3.27, 95\% CI $(2.05,5.21$ ), low job control (AOR:2.25, 95\% CI $(1.21,4.20)$ and age $<28$ (AOR:0.25, 95\% CI $(0.10,0.63)$ were the factors associated with work-related stress. The result reviewed that the prevalence of work-related stress was high and higher emphasis required on job demand, job control, and cigarette smoking to ease the burden of work-related stress factors. Recommendation was made that other causes of WRS, such as working conditions and further large-scale study, be considered for future research. The present study and reviewed study were related in the usage of respondent, although differs in area of study as the reviewed study was done in Ethiopia while the present study was done in Nigeria. Also, research designs, statistical tools used in analyzing data and the instrument used for data collection.

Olanrewaju (2015) conducted a study on Predictive Influence of Job Stress on Mental Health and Work Behaviour of Nurses in the University College Hospital, Ibadan, Oyo State, Nigeria. Descriptive research design was used in the study. Three hundred respondents were selected from the nurses of the University College Hospital, Ibadan Area of Oyo State, Nigeria. The respondents were measured with relevant standardized scale (instruments) which has a revalidated reliability coefficient of .80 and the data obtained was analyzed using the Pearson Product Moment Correlation Coefficient (PPMC) statistical analysis of the Statistical Package for the Social Science (SPSS). Two research hypotheses were raised and answered in the study. The result showed that there was significant relationship between the job stress and the mental health of nurses in the hospital $(\mathrm{r}=.828 ; \mathrm{P}<0.05)$ and that there was significant relationship between the job stress and work behaviour of nurses in the hospital $(\mathrm{r}=.867$; $\mathrm{P}<0.05)$. On the strength of these findings, it was stressed and advocated the need to ensure that efficient nursing care is given to the patients, the government (Federal, State) the Ministries of Health or the hospital management boards should help in reducing sources of stress in the nurses. Their working conditions need to be quickly improved by giving them adequate salary that commensurate with the demands of their jobs. Both studies investigated both occupational stress as predictor of mental health but differs in respondents, research design, area of study and statistical tool used to analyze data.

\section{Methods}

The study adopted correlation survey research design. The population of the study comprises of all Lectures from 26 universities in south-east Nigeria (5 Federal universities, 6 state universities and 15 private universities). A sample of 920 Lecturers was selected through the multi-stage sampling technique. Simple random sampling technique of balloting with replacement type was used to select 3 universities from state sampled, resulting in 15 selected universities in all. Disproportionate stratified sampling technique was employed in selecting 184 Lecturers from each state in South-East Geopolitical zone in Nigeria. The instrument adopted for data collection is the Occupational Stress Inventory Revised Edition (OSI-R) which was developed by Samuel H. Osipow in 1998 and The Depression Anxiety Stress Scale (DASS-21) developed by Lovibond and Lovibond in 1983.

The Occupational Stress Inventory Revised Edition (OSI-R) was revised from the Occupational Stress Inventory (OSI). The OSI-R is a concise measure of three subscales on occupational adjustment with 60-item Occupational Roles Questionnaire (ORQ), the 40-item Personal Strain Questionnaire (PSQ), and the 40-item Personal Resources Questionnaire (PRQ). The OSI-R has been widely used in 60 studies in various contexts. Participants were asked to rate how well the statement fitted them on a scale from 1 (rarely or never true) to 5 (true most of the time). Good internal consistency scores were reported for OSI-R with Cronbach alpha of .88, .93 and .89 for ORQ, PSQ, and PRQ, respectively. In the present study, a Cronbach alpha coefficient stood at .91 for the whole scale and .87 for ORQ, .86 for PSQ and .87 for PRQ.

The Depression Anxiety Stress Scale (DASS-21) developed by Lovibond and Lovibond in 1983 is a short version of the instrument (originally 42 items) used to measure the negative emotional states of depression, anxiety and stress. This instrument will be adopted by the present study to measure mental health. The instrument has been widely used by other scholars. Participants were asked to rate how much the statement applied to them in the past week on a 4-point scale from 0 (does not apply to me at all) to 3 (applied to me very much, or most of the time). Good psychometric properties were reported on the short DASS-21 version yielded a Cronbach alpha statistic of .94 .87 and .91 for depression, anxiety and stress, respectively. Cronbach alpha coefficient in a study by Leung, Mak, Chui, Chiang and Lee (2009) in the present study was .95 for the whole scale and $.90, .85$, and .86 for stress, depression, and anxiety, respectively.

The administration of the instrument was done through direct delivery approach to the Lectures, in administering the instrument, A total of $920(100 \%)$ questionnaires were administered with a retrieval rate of 902 (98\%). Data collected were analyzed using multiple regression analysis. In testing the hypothesis, where p-value is greater than the significant value 0.05 , the null hypothesis will not be rejected; otherwise, where $p$-value is lesser than the significant value 0.05 , the null hypothesis will be rejected. This analysis was computed using the Statistical Package for Social Sciences version 21 (SPSS 21). 


\section{Results}

4.1 Research question 1: Does occupational stress predict mental health of university Lecturers in South-east, Nigeria between $20-40$ years of age?

4.2 Hypothesis 1: There is no significant relationship between occupational stress and mental health of University Lecturers in South-east, Nigeria between 20 - 40 years of age below.

Table 1: Summary of regression analysis on occupational stress as predictor of mental health of university lecturers $(N=184)$

\begin{tabular}{|l|l|l|l|l|l|l|l|l|l|l|}
\hline Variable & $\mathrm{R}$ & $\mathrm{R}^{2}$ & $\begin{array}{l}\mathrm{R}^{2} \\
\text { Change }\end{array}$ & $\mathrm{B}$ & BETA & Cal. F & $\begin{array}{l}\text { Cal. } \\
\mathrm{t}\end{array}$ & $\mathrm{df}$ & Pvalue & Remark \\
\hline $\begin{array}{l}\text { Occupational } \\
\text { stress }\end{array}$ & 0.85 & 0.732 & 0.730 & -.065 & .510 & 308.99 & 9.65 & 182 & 0.000 & $\mathrm{~S}$ \\
\hline
\end{tabular}

In Table 1 it was observed that occupational stress of lecturers had Beta of 0.510. This indicates that occupational stress of lecturers between 20-40 years of age had contributed to 51.0 percent of their mental health. Also, at $182 \mathrm{df}$ and 0.05 level of significant, the calculated $\mathrm{t} 9.65$ with Pvalue 0.000 which is less than the 0.05 , the first null hypothesis is rejected. Therefore, occupational stress of lecturers between 20-40 years of age is a significant predictor of their mental health.

4.3 Research Question 2: Does occupational stress predict mental health of university Lecturers in South-east, Nigeria between 40 years and above?

4.4 Hypotheses 2: There is no significant relationship between occupational stress and mental health of University Lecturers in South-east, Nigeria within 40 year above.

Table 2: Summary of regression analysis on occupational stress as predictor of mental health of university lecturers $(N=184)$

\begin{tabular}{|l|l|l|l|l|l|l|l|l|l|l|}
\hline Variable & $\mathrm{R}$ & $\mathrm{R}^{2}$ & $\begin{array}{l}\mathrm{R}^{2} \\
\text { Change }\end{array}$ & $\mathrm{B}$ & BETA & Cal. F & $\begin{array}{l}\text { Cal. } \\
\mathrm{t}\end{array}$ & $\mathrm{df}$ & Pvalue & Remark \\
\hline $\begin{array}{l}\text { Occupational } \\
\text { stress }\end{array}$ & 0.866 & 0.749 & 0.746 & .393 & .720 & 273.97 & 1.72 & 182 & 0.000 & $\mathrm{~S}$ \\
\hline
\end{tabular}

In Table 2 it was observed that occupational stress of lecturers had Beta of 0.720 . This indicates that occupational stress of lecturers within 40 years and above had contributed to 72.0 percent of their mental health. Also, at $182 \mathrm{df}$ and 0.05 level of significant, the calculated t 1.72 with Pvalue 0.000 which is less than the 0.05 , the second null hypothesis is rejected. Therefore, occupational stress of lecturers within 40 years of age is a significant predictor of their mental health.

4.5 Research Question 3: How does occupational stress and age jointly predict mental health of university Lecturers in South-east, Nigeria?

4.6 Hypotheses 3: There is no significant relationship among occupational stress, Age and mental health of University Lecturers in South-east, Nigeria.

Table 3: Summary of regression analysis on occupational stress and age as joint predictors of mental health of university lecturers $(N=184)$

\begin{tabular}{|l|l|l|l|l|l|l|l|l|l|l|}
\hline Variable & $\mathrm{R}$ & $\mathrm{R}^{2}$ & $\begin{array}{l}\mathrm{R}^{2} \\
\text { Change }\end{array}$ & $\mathrm{B}$ & BETA & Cal. F & Cal. t & df & Pvalue & Remark \\
\hline $\begin{array}{l}\text { Occupational } \\
\text { stress }\end{array}$ & 0.176 & 0.028 & 0.027 & 0.148 & .720 & 84.54 & 6.733 & 182 & 0.000 & $\mathrm{~S}$ \\
\hline Age & & & & -.095 & .062 & & & & & \\
\hline
\end{tabular}

In Table 3 it was observed that occupational stress of lecturers had Beta of 0.720, while Age had BETA of 0.62. This indicates that occupational stress of lecturers jointly with age had contributed to 72.0 percent and 6.2 percent respectively of their mental health. Also, at $182 \mathrm{df}$ and 0.05 level of significant, the calculated t 6.733 with Pvalue 0.000 which is less than the 0.05 , the third null hypothesis is rejected. Therefore, occupational stress and age of lecturers is a significant joint predictor of their mental health.

\section{Discussion}

The result presented revealed that occupational stress of lecturers between 20-40 years of age had contributed to 51.0 percent of their mental health. Also, occupational stress of lecturers between 20-40 years of age is a significant predictor of their mental health. This finding disagrees with the findings of Adenuga (2015) who reported that there is no significant relationship in the occupational stress and mental health of bank employees. However, both studies conform when it reported that that there is significant relationship in the occupational stress and job satisfaction of bank employees, and occupational stress predicted job satisfaction and mental health. This could be as a result of the age range of these lecturers. This is visible as most of these lecturers work extra-time with excess workload in other to cover up for a particular academic session.

The result further revealed that occupational stress of lecturers within 40 years and above had contributed to 
72.0 percent of their mental health. Also, the occupational stress of lecturers within 40 years of age is a significant predictor of their mental health. These findings are in disagreement with the findings of Agbor, Ebeh and Onyeanu (2018) who found that academic stress, substance abuse and age had significant negative relationship with mental wellbeing whereas mental wellbeing did not differ across gender $(\mathrm{P}<.01)$. However, the findings agree with the study of Kabito et al (2020) as they reported that the result reviewed that the prevalence of work-related stress was high and higher emphasis required on job demand, job control, and cigarette smoking to ease the burden of workrelated stress factors. This could be hinged on the scenario that lectures with higher age brackets (40 and above) are saddled with great responsibilities within the school system based on their experience overtime. These ranges from appointments among others.

The findings of this study further revealed that that occupational stress of lecturers jointly with age had contributed to 72.0 percent and 6.2 percent respectively of their mental health. Similarly, occupational stress and age of lecturers is a significant joint predictor of their mental health. These findings align with the findings of Olanrewaju (2015) who reported that there was significant relationship between the job stress and the mental health of nurses in the hospital and that there was significant relationship between the job stress and work behaviour of nurses in the hospital. The issue of mental health has been a prevailing issue within and outside the school environment. In view of this findings, lecturers in the school environment are individuals who seems to be faced with the most duties in office and after work, hence such occupational stress has its toll on their mental health.

\section{Conclusion}

In view of the outcome of the findings reported, occupational stress has a high percent prediction of lecturers' mental health status, also occupational stress and age jointly predicts metal health status of lectures at different levels. This is said to be as a result of the increase in workload and less time for relaxation and social engagements.

\section{Recommendations}

Based on the strength of the findings, it was recommended that

- Extra work package such as incentives should be provided for lecturers in tertiary institutions.

- $\quad$ Routine medical check on the mental health status of lecturers should be sponsored by federal and state governments for lecturers in federal and state institutions respectively.

- Qualified lecturers should be constantly employed to help ease the workload on existing lecturers

\section{References}

Adebiyi, D. (2011). Prevalence of Stress among University of Ado-Ekiti Lecturer. Unpublished Thesis.

Adebiyi, D. R. (2013). Occupationa stress among academic staff of Ekiti state university, Ado Ekiti. European Scientific Journal, 9(4), 202-208.

Adenuga, O. A. (2015). Impact of Occupational Stress on Job Satisfaction and Mental Health of First Bank Employees: Implication for Personnal Psychologists. American Journal of Psychologist and Cognitive Science, 1(1), 15-21.

Adenuga, O. A. (2015). Impact of occupational stress on job satisfaction and mental health of first bank employees: implication for personnes psychologists. American journal of Psychology and Cognitive Science, 1(1), 15-21.

Agbor, N. S., Ebeh, R., \& Onyeanu, M. (2018). Predictors of mental health wellbeing among undergraduates in eastern Nigeria: A function of academic stress, substance abuse and age. African Journal of Social and Behavioural Sciences, 8(2), 142-150.

Akinmayowa, J., \& Kadiri, P. (2014). Stress among Academic Staff in a Nigerian University. Covenant Journal of Business and Social Sciences, 65(1), 73-91.

Alex, A. (2019). Academics highlight flaws in annual accreditation process. Retrieved from https://www.universityworldnews.com/post.php?story=20191203110613770. $\quad$ Retrieved from universityworldnews web site: https://www.universityworldnews.com/post.php?story=20191203110613770

Dykstra, P., \& Fleischmann, M. (2018). Are societies with a high value on the Active Ageing Index more age integrated? In Building Evidence for Active Ageing Policies: Active Ageing Index and Its Potential. Singapore: Springer Nature.

Kabito, G., Wami, S., Chercos, D., \& Mekonnen, T. (2020). Work-related Stress and Associated Factors among Academic Staffs at the University of Gondar, Northwest Ethiopia: An Institution based based based Crosssectional Study. Ethiopia Journal Health, 30(2), 223-232.

Leung, S. S., Mak, Y. W., Chui, Y. Y., Chiang, V. C., \& Lee, A. C. (2009). Occupational stress, mental health status and stress management behaviours among secondary school teachers in Hong Kong. Health Education Journal, 68(4), 328-343.

Mahmood, A., Saira Nudrat, S., \& Zahoor, F. (2013). Impact of Age and Level of Experience on Occupational Stress of Academic Managers at Higher Educational Level. Mediterranean Journal of Social Sciences, 4(1), $536-541$ 
Nwimo, I. O., \& Onwunaka, C. (2015). Stress among secondary school teachers in Ebonyi state, Nigeria: Suggsted interventions in the worksite Milieu. Journal of Education and Practice, 6(26), 93-100.

Olanrewaju, M. (2015). Predictive Influence of Job Stress on Mental Health and Work Behaviour of Nurses in the University College Hospital, Ibadan, Oyo State, Nigeria. Research on Humanities and Social Sciences, 5(11), 31-38.

Ukpai, U. \&. (2016). Current Challenges and the Needed Competences in the management Of University Education in Nigeria. British Journal of Education, 4(2), 74-86.

Walker, A. (2015). The concept of active ageing. In A. A. Walker, Active Ageing in Asia (pp. 11-23). London, UK: Taylor \& Francis Group: New York.

World Health Organisation and International Labour Organisation (May 18,2021). World Health Organisation Survey. 